\title{
Anaesthetic management of a pregnant patient with von Willebrand's disease - a Case Report
}

Alves, DR ${ }^{1}$; Franco, S²; Saldanha, L ${ }^{2}$ ( ${ }^{1}$ Anaesthesiology resident; ${ }^{2}$ Anaesthesiology Fellow)

Centro Hospitalar de Lisboa Ocidental, Portugal; Head of Department: Manuel Chedas

Introduction: Being the most frequent inherited bleeding disorder (1-2\% prevalence in the general population ${ }^{1}$ ), von Willebrand's disease (vWD) is likely to be encountered by Anaesthesiologists in their daily clinical practice. It is characterized by either quantitative or qualitative abnormalities in von Willebrand Factor (vWF), a molecule involved in both the adhesion of platelets to the exposed subendothelium and in the binding of circulating Factor VIII, thus significantly increasing its half-life. There are 3 types $^{2}$ of vWD, the most common of which is type 1, responsible for $80 \%$ of cases and characterized by a quantitative deficit of vWF.

\begin{tabular}{|c|l|}
\hline Type & \multicolumn{1}{|c}{ Pathophysiology } \\
\hline 1 & Quantitative deficit in vWF \\
\hline 2 & Functional deficit in vWF (either in \\
$(2 \mathrm{~A}, 2 \mathrm{~B}, 2 \mathrm{M}$, & $\begin{array}{l}\text { multimer composition or in its ability to } \\
\text { interact with FVIII) }\end{array}$ \\
\hline 3 & Severe vWF deficiency $(<10 \%)$ \\
\hline
\end{tabular}

Table 1 - Types of von Willebrand's Disease.

Case report: 29-year-old, primiparous, ASA 2 patient with known type $1 \mathrm{vWD}$, presenting to hospital in labour. She had been diagnosed as having vWD at the age of 13 (study of menorrhagia), and needed no specific maintenance treatment. Throughout pregnancy there was no clinical history of either spontaneous or provoked mucocutaneous bleeding, and she was timely referred to a Haematology consult as an outpatient. vWF levels in the third trimester showed to be supranormal, and there were no changes either in clotting times nor in platelet levels. Haematology considered there to be no indication for desmopresin use nor contraindication to neuroaxial techniques.

A first stage, latent phase of labour was identified on arrival and, considering all of the above, a combined spinal epidural was performed at the L3-L4 interspace with a needle through needle approach (18G Tuohy needle, $27 \mathrm{G}$ pencil-point spinal needle). The patient eventually proceeded to caesarean section for non-progression of labour, for which anaesthesia was provided via the previously placed epidural catheter. There wasno excessive blood loss either intra- or postoperatively. The epidural catheter was removed $24 \mathrm{~h}$ after surgery, and the patient discharged home uneventfully on the $3^{\text {rd }}$ postoperative day. Close neurologic monitoring throughout the hospital stay evidenced no changes.

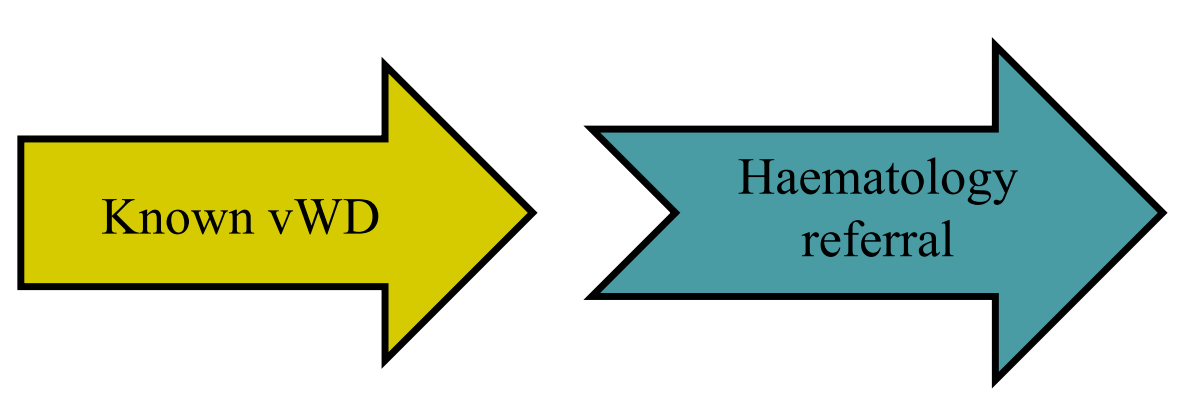

History and examination

vWF levels (antigen + activity); F VIII activity

Family history and screening/counseling
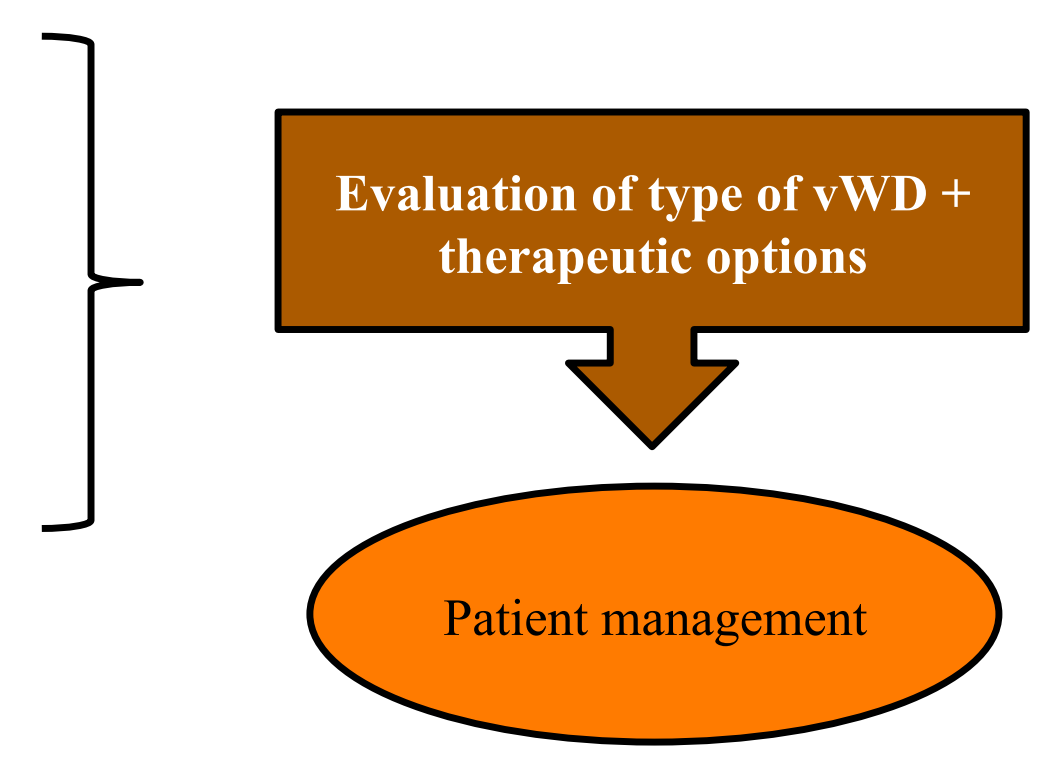

Figure 1 - Summary of patient approach in this case.

Discussion: During late pregnancy the levels of several clotting factors tend to increase as a preparation for labour, namely fibrinogen, FVII, FVIII, FX and $\mathrm{vWF}^{3}$ (see Table 2).

In type $1 \mathrm{vWD}$, where there is a lower level of normally functioning $\mathrm{vWF}$, this means that the disease can actually normalize the deficient factor's levels towards the peripartum period, with a temporary correction of the increased bleeding tendency. Appropriate haematological referral and follow-up is instrumental in these cases, allowing for a proper characterization of the disease, vWF and F VIII levels, and revealing that neuroaxial techniques are not necessarily contraindicated, at least in type 1 disease.

\section{Learning points:}

- Bleeding risk must be assessed before any neuroaxial technique;

- vWD usually entails an increased bleeding risk by itself, but there is a wide spectrum of disease severity;

- In type $1 \mathrm{vWD}$ the defect is quantitative, and thus may be "normalized" by the prothrombotic state of late pregnancy, thus not constituting a contraindication to neuroaxial techniques;

- Given the heterogeneity within the disease spectrum, however, it is fundamental to make sure these patients are appropriately and timely studied by a specialist to assess and weigh available therapeutic options.

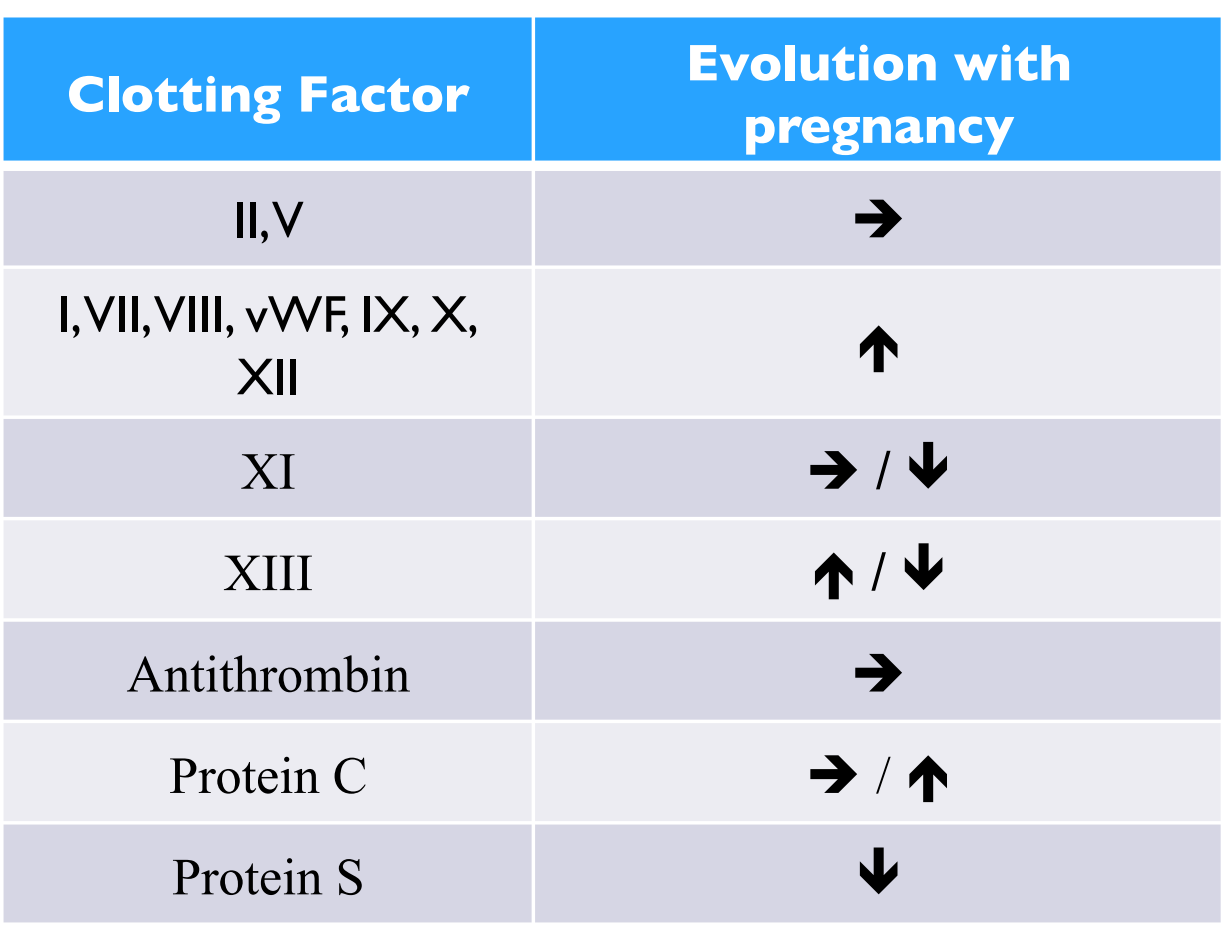

Table 2 - Normal evolution of clotting factor levels in late pregnancy. (Adapted from Prisco et al. ${ }^{4}$ )
References

1. Butwick AJ, Carvalho B. Neuraxial anesthesia for cesarean delivery in a parturient with type 1 von Willebrand disease and scoliosis. J Clin Anesth. 2007;19:230-233.

2. Marrache D, Mercier FJ, Boyer-Neumann C, Roger-Christoph S, Benhamou D. Epidural analgesia for parturients with type 1 von Willebrand disease. Int J Obstet Anesth. 2007;16:231-235.

3. James AH. More than menorrhagia: a review of the obstetric and gynaecological manifestations of von Willebrand disease. Thromb Res. 2007;120 Suppl 1:S17-20.

4. Prisco D, Ciuti G, Falciani M. Hemostatic changes in normal pregnancy. Haematol Rep. 2005;1:1-5. 